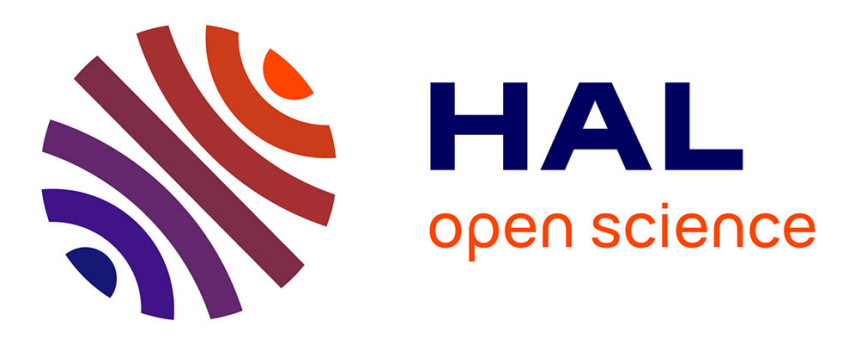

\title{
Surface impedances, BIEM and FEM coupled with 1D non linear solutions to solve 3D high frequency eddy current problems
}

Laurent Krähenbühl, Olivier Fabrègue, Sven Wanser, Manuela de Sousa Dias, Alain Nicolas

\section{To cite this version:}

Laurent Krähenbühl, Olivier Fabrègue, Sven Wanser, Manuela de Sousa Dias, Alain Nicolas. Surface impedances, BIEM and FEM coupled with 1D non linear solutions to solve 3D high frequency eddy current problems. IEEE Transactions on Magnetics, 1997, 33 (2), pp.1167-1172 Part 2. hal-00140677

\section{HAL Id: hal-00140677 \\ https://hal.science/hal-00140677}

Submitted on 23 Apr 2007

HAL is a multi-disciplinary open access archive for the deposit and dissemination of scientific research documents, whether they are published or not. The documents may come from teaching and research institutions in France or abroad, or from public or private research centers.
L'archive ouverte pluridisciplinaire HAL, est destinée au dépôt et à la diffusion de documents scientifiques de niveau recherche, publiés ou non, émanant des établissements d'enseignement et de recherche français ou étrangers, des laboratoires publics ou privés. 


\title{
Surface Impedances, BIEM and FEM Coupled with 1D Non Linear Solutions to Solve 3D High Frequency Eddy Current Problems
}

\author{
Laurent Krähenbühl*, Olivier Fabrègue*, Sven Wanser*, Manuela De Sousa Dias** and Alain Nicolas* \\ * CEGELY(") - Ecole Centrale de Lyon - BP 163 - F 69131 Ecully Cedex (France) - e-mail: krahenb@trotek.ec-lyon.fr \\ ** Renault SA - Industrial Engineering Department - F 92109 Boulogne-Billancourt Cedex (France)
}

\begin{abstract}
The BIEM coupled with surface impedances gives good results at a low cost for 3D high frequency eddy-currents calculation with linear materials.

In this paper, we review the possible extensions to non linear materials. We propose (and test in 3D) an original method, based on $1 D$ computations of the complex surface impedance. Results are applied to induction hardening processes. This paper presents essentially validations of the method of non linear surface impedances; a future publication will be devoted to the thermal validation.
\end{abstract}

\section{INTRODUCTION}

In principle, the magnetodynamics (problem of computing exactly how eddy-currents flow inside a conducting body) has to be solved with the Finite Element Method. The association with Boundary Integral Equations may be useful to take into account an external and non conductive region.

However, if the frequency is sufficiently high, the skin effect could be sufficient to turn the 3D problem into a simpler shell problem. This property is industrially used, particularly for metallurgic proceedings (surface hardening of steel). Numerically, the field inside the material is taken as zero; the skin depth is neither meshed, nor explicitly described: then the regular volume FEM is no more used for the conducting area, and the magnetodynamic effect has to be expressed in an adequate boundary equation.

For linear materials, we will use the analytic ID solution (descending exponential) to find the equivalent boundary equation. For saturable materials, there is no exact analytic solution. Agarwal [3] proposed an approximated solution, only valid for strong saturated media. In this paper, we propose to solve the non linear equation in $1 \mathrm{D}$ with a numerical method. We will deduce from this solution an equivalent value of the complex surface impedance on each node of the surface mesh of the magnetodynamic problem.

As for us, we use the BIEM for the 3D magnetic computation outside the conducting area, but the proposed method (non linear equivalent surface impedance) could be used with finite elements. The thermal resolution calls a separate thermal software: the coupling is done by projection

Manuscript received March $18,1990$.

(1) Cegely: Centre de Génie Electrique de Lyon. Unité propre de recherche de l'enseignement supérieur, associéc au CNRS (1n' 5005).

This work was supported in part by Electricité de France (Applications de l'Electricites) and by Renautr S.A. (Applications Industrielles). The authors wish to express their thanks to DTII and CEDRAT for their help in using their softwares (respectively FLUX Expert and FLUX2J)). and interpolation of data from magnetic to thermal and reciprocally: no particular compatibility between the two softwares is required.

\section{SURFACE IMPEDANCE METHOD AND BIEM/FEM}

The same numerical method will not he used everywhere : the problem of field calculation is separated in two domains : domains with and without eddy currents (air).

\section{A. Non-conducting areas : $3 D$ BIEM.}

In non-conducting areas, the magnetodynamic problem is expressed in terms of scalar potential with the Boundary Integral Equations Method [1]:

$\overrightarrow{\mathrm{H}}_{0}$ : source field $[\mathrm{A} / \mathrm{m}]$

$\mathrm{V}:$ scalar potential [A]

$\overrightarrow{\mathrm{H}}=\overrightarrow{\mathrm{H}}_{0}-\vec{\nabla} \mathrm{V}:$ magnetic field $[\mathrm{A} / \mathrm{m}]$

The BIE for region $\mathrm{R}$ (boundary $S$, permcability $\mu_{0} \mu_{i}$ ) is :

$\Omega_{S}(P) \cdot V(P)=-\oint_{S}\left[V(Q) G_{P}^{\prime}(Q)-V^{\prime}(Q) G_{P}(Q)\right] \cdot d s$

with :

$\mathrm{P}$ : observation point, on or outside the boundary

$\mathrm{Q}$ : integration point on "ds"

$\Omega_{S}(P)=-\oint_{S} G_{P}^{\prime}(Q) \cdot d s:$ angular factor for $P$ and $S$.

$G_{P}(Q)=\frac{1}{4 \pi r}:$ Green's function for $\Delta$

$G_{p}^{\prime}(Q)=\left.\vec{\nabla} G_{p} \cdot \vec{n}\right|_{Q}=\frac{\vec{r} \cdot \vec{n}}{4 \pi r^{3}}:$ normal derivative of $G$

$\mathrm{V}^{\prime}(\mathrm{Q})=\left.\vec{\nabla} \mathrm{V} \cdot \overrightarrow{\mathrm{n}}\right|_{\mathrm{Q}}$ : normal derivative of $\mathrm{V}$ on $\mathrm{Q}$

$\overrightarrow{\mathrm{r}}=\overrightarrow{\mathrm{PQ}} ; \mathrm{r}=\mathrm{PQ}[\mathrm{m}]$

$\vec{n}=$ normal vector, exterior to $S$

This boundary integral equation can be written in terms of scalar potential and normal flux density, using :

$\mathrm{B}_{\mathrm{n}}(\mathrm{Q})=\left.\mu_{0} \mu_{\mathrm{r}}\left[\overrightarrow{\mathrm{H}}_{0}-\vec{\nabla} \mathrm{V}\right] \cdot \overrightarrow{\mathrm{n}}\right|_{\mathrm{Q}}$ : normal flux density on $\mathrm{Q}$

$V^{\prime}(Q)=\vec{H}_{0} \cdot \vec{n}-\frac{B_{n}(Q)}{\mu_{0} \mu_{r}}$ 
Phenomena inside the conducting material are projected in a simple boundary equation [2] by the surface impedance method:

$$
B_{n}=\frac{1}{j \omega} \vec{\nabla}_{s} \cdot\left(\underline{Z}_{s} \vec{H}_{s}\right)
$$

where:

$\underline{Z}_{s}$ : surface impedance, defined by:

$\overrightarrow{\mathrm{E}}_{s}=\underline{\mathrm{Z}}_{s}\left(\overrightarrow{\mathrm{H}}_{s} \times \overrightarrow{\mathrm{n}}\right)$

$\overrightarrow{\mathrm{E}}_{\mathrm{s}}$ : electric field, tangent to $\mathrm{S}$

$f=\omega / 2 \pi:$ frequency of the source $\vec{H}_{0}$

$\vec{\nabla}_{s}$ : surface restriction of $\vec{\nabla}$.

$$
\text { [i.e. : } \vec{\nabla}_{s} \cdot \vec{X}=\vec{\nabla} \cdot \vec{X}-\frac{\partial(\vec{X} \cdot \vec{n})}{\partial \mathrm{n}} \text { ] }
$$

The boundary differential equation (4) can also be written in terms of normal flux density and scalar potential, as we did it for the 3D BIE

$$
\vec{\nabla}_{s} \cdot\left(\underline{Z}_{s} \vec{\nabla}_{s} V\right)=j \omega B_{n}-\vec{\nabla}_{s} \cdot\left(\underline{Z}_{s} \vec{H}_{0 . s}\right)
$$

This equation can be treated with the finite element method: the matrix terms for a node « $\mathrm{i} »$ of an element « $\mathrm{El} »(\mathrm{M}$ nodes) is :

$\sum_{j=1 . M}\left\{j \omega \vec{B}_{j} \cdot \vec{n}_{j} \int_{E l} \alpha_{i} \alpha_{j} d s+V_{i} \sum_{k=1 . M}\left[\underline{Z}_{k} \int_{E l}\left(\vec{\nabla} \alpha_{i} \cdot \vec{\nabla} \alpha_{j}\right) \alpha_{k} d s\right]\right\}$

$=\vec{H}_{0 i} \cdot \sum_{k=1 . M} Z_{k} \int_{E J}\left(\vec{\nabla} \alpha_{i}\right) \alpha_{k} d s$

where $\alpha_{i}, \alpha_{i}, \alpha_{k}$ are the shape functions.

The same mesh (second order quadrangles) is used for the 3D Boundary Integral Equation and for the surface Finite Element equation, and they are solved together.

\section{Surface impedance and surface power density.}

The question is to obtain a good value for the surface impedance: it depends on the material itself, but also on the temperature and, for ferromagnetic materials, on the modulus of the field $\mathrm{H}$ on each point of the surface.

In the linear case, the regular result is:

$$
\begin{aligned}
& \underline{Z}_{\text {s.lin }}=\frac{1}{\sigma \delta_{\operatorname{lin}}} \cdot(I+\mathrm{j}) \text { with: } \delta_{\mathrm{lin}}=\sqrt{\frac{2}{\sigma \omega \mu}} \\
& \sigma: \text { conductivity }
\end{aligned}
$$

This expression is linked to the usual idea of skin depth $\delta_{\text {lin. }}$.

The surface power density through $\mathrm{S}$ is given by the flux of Maxwell's tensor $\underline{\text { : }}$

$$
\underline{s}=p+j \cdot q=\left(\underline{\vec{E}} \wedge \underline{H}^{*}\right) \cdot \vec{n}
$$

Using expression (5) of $\underline{Z}_{s}$, we obtain :

$$
Z_{\mathrm{s}}=(p+j . q) / \mathrm{H}_{s}^{2}
$$

Consequently, the $(1+j)$ factor in (8) means that active and reactive power going inside the conducting region are equal.

\section{A. Agarwal's theory.}

In non-linear cases, this «surface impedance» method cannot be exact : even if the source field $\mathrm{H}_{0}$ is sinusoidal, electric field $E$ and flux density $B$ are no more sinusoidal. Nevertheless we will show that good results can be obtained with modified values of the surface impedance.

Agarwal has proposed in year 59 in a very famous paper [3] the value:

$$
\begin{aligned}
& \underline{Z}_{\mathrm{S} . \mathrm{Ag}}(\hat{\mathrm{H}})=\frac{4}{3 \pi \sigma \delta_{\mathrm{Ag}}(\hat{\mathrm{H}})}(2+\mathrm{j}) \\
& \text { with: } \delta_{\mathrm{Ag}}(\hat{\mathrm{H}})=\sqrt{\frac{2}{\sigma \omega \mathrm{B}_{\mathrm{Ag}}(\hat{\mathrm{H}}) / \hat{\mathrm{H}}}}
\end{aligned}
$$

This result was obtained analytically for an ideal rectangular $\mathrm{B}-\mathrm{H}$ curve (Fig, $I$ and 2 ) and $\mathrm{H}$ sinusoidal. The electric field on the surface is no more sinusoidal (Fig. 3); the Agarwal's surface impedance is linked to its first harmonic term. This simplification is justified considering the energy: this term gives the same mean power as the complete Fourier's development.

Nevertheless this theory is only valid for strongly saturated iron. Agarwal himself proposed a heuristic coefficient $(0.75$ !) to find the saturation flux density $\mathrm{B}_{\mathrm{Ag}}$ from the static magnetization curve.

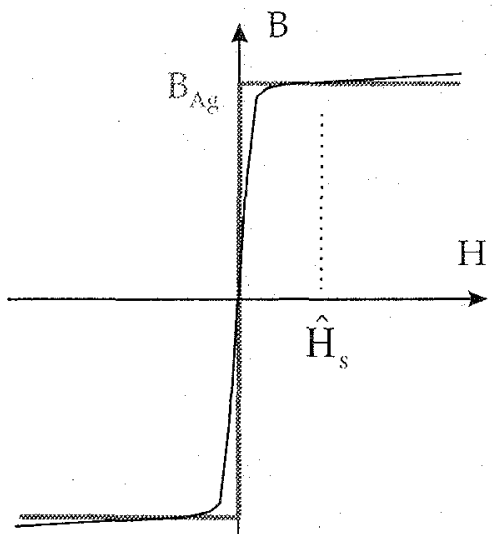

Fig. 1: Agarwal's B-H curve.

\section{B. Balanced method.}

In real 3D structures, some areas are strongly saturated, while other are not: Guérin [4] proposes recently to combine linear and Agarwal's models, with coefficients taking into account the degree of saturation:

$$
\underline{Z}_{\mathrm{s}, \mathrm{Gu}}=\alpha(\hat{\mathrm{H}}) \cdot \underline{Z}_{\mathrm{sin}}+[1-\alpha(\hat{\mathrm{H}})] \underline{Z}_{\mathrm{s}, \mathrm{Ag}}
$$

He uses this expression in a 3D-FE software and obtains interesting results; however, the choice of function $\alpha$ remains unsolved. 


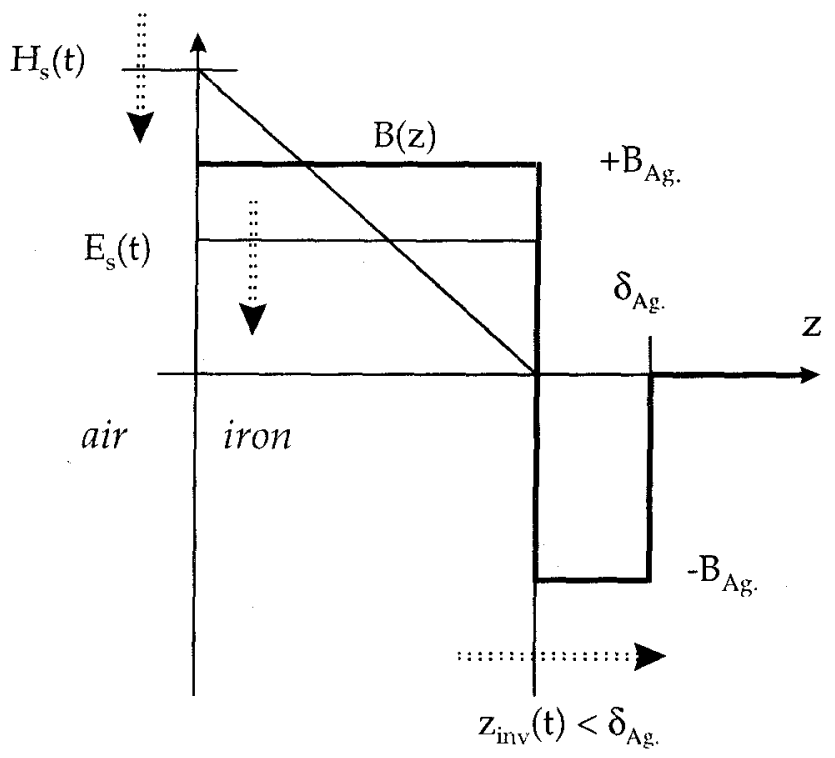

Fig. 2: Agarwal's theory:

Fields $B(t), H(t)$ and $E(t)$ as functions of depth $z$

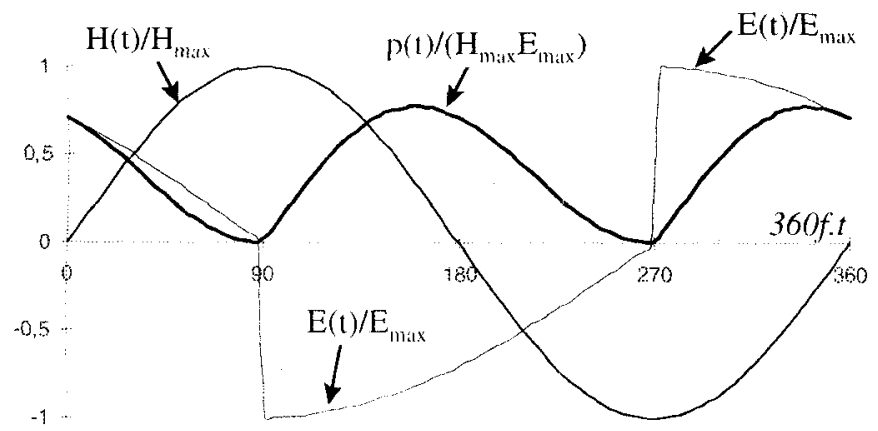

Fig. 3: Agarwal's theory

surface fields $E(t)$ and $H(t)$ and resulting power $p(t)$

\section{PRE-CALCUlations USING ID FEM}

In 86, A. Bossavit [5] solved the magnetothermal problem in $1 \mathrm{D}$, with a more realistic B-H curve, finite elements for space domain and step by step for time domain, but it was for a pedagogical purpose. We propose to use such numerical ID solution to build the complex surface impedance as a function of the peak value of $H_{s}$, for each material and for each temperature (that means for each $\mathrm{B}-\mathrm{H}$ curve, and for each value of the conductivity). Then, real and imaginary parts arise from power equivalency. In particular, this method gives correct results for the passage from low to strong fields.

\section{A. ID-equation, FE-discretization and periodic solution.}

Reduced in 1D, the equation of eddy currents simply becomes:

$$
\frac{\partial^{2} \mathrm{H}(\mathrm{z}, \mathrm{t})}{\partial \mathrm{z}^{2}}=\sigma \frac{\partial \mathrm{B}[(\mathrm{H}(\mathrm{z}, \mathrm{t}))]}{\partial \mathrm{t}}
$$

This equation is in principle easy to solve by a finite elements or finite differences method, in 1D for space and step by step for time (it is necessary to discretize at least 2 Agarwal's skin depths).

In practice, two difficulties are however encountered:

1. The solution approached by Agarwal shows the complex hehavior of the real solution, in $z$ as in $t$ (for example, the front of abscissa $z_{\text {inv }}$ moves ...). A precise solution requires a very fine discretization of space and time (typically more than 50 steps by period, and at least as much for space)

2. Only the stable solution concerns us. To reach it, it is necessary to wait up to the end of the transient phenomenon. The algorithm has been accelerated by forcing the solution to be periodic, and by using the calculation of successive periods as iterations for the non linearity. The temporal derivatives and values of the non-linear properties are estimated from the solution to the previous half period. Furthermore, the direct component of field is canceled after each period.

Figure 4 gives examples of behaviors of electric and magnetic fields as functions of depth, at different instants and for sinusoidal variations of the surface magnetic field. The comparison with schematic results of figure 2 enables to understand the respective parts taken by linear and non linear phenomena. The time variations of electric field (Fig. 5) gives access to the complex power density [(9), Fig. 6] and to the surface impedance (10).

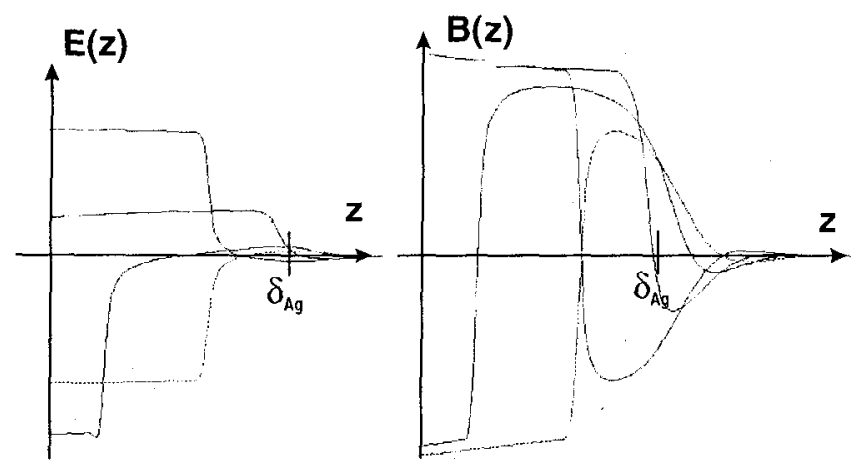

Fig. 4: ID-FEM solution: example of $\mathrm{z}$ variations (for different time steps).

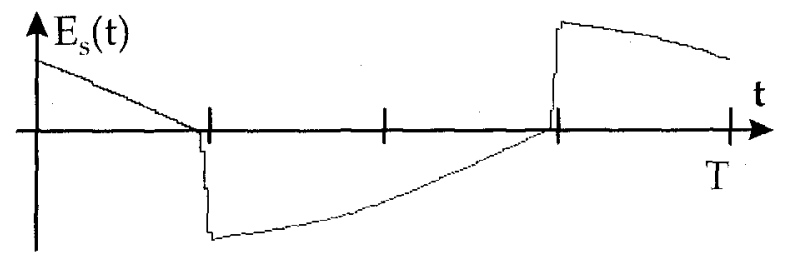

Fig. 5: 1D-FEM solution: surface electric field $E$ ( $t$ ) (example). 


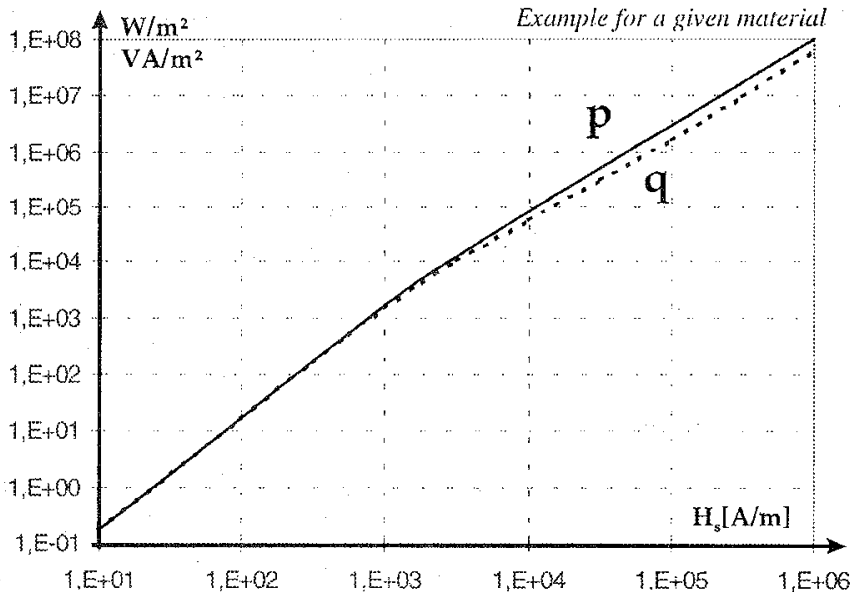

Fig. 6: example of active and reactive power densities, as functions of the surface magnetic field

\section{B. Data-base, tabulation and extrapolation.}

In practice, we have to compute the values of the surface impedance on each node of the mesh, for all time-steps and for all non linear iterations: it may be expensive! However, the variations of the active and reactive power densities (for a particular B-H curve and for a given frequency) as function of the magnetic field are very simple (Fig. 6). By the fact, for a given temperature, ten values or so (for example 2 values per decade) are sufficient to tabulate (then interpolate) $p$ or $q$ with a very good accuracy as function of $\mathrm{H}$.

The behavior of the surface impedance as function of temperature and frequency is as well smooth; finally a few hundreds of coefficients are sufficient to describe a given material. They can be computed once and for all.

Then, the values which are useful during the 3D computation can be easily and quickly extracted and interpolated

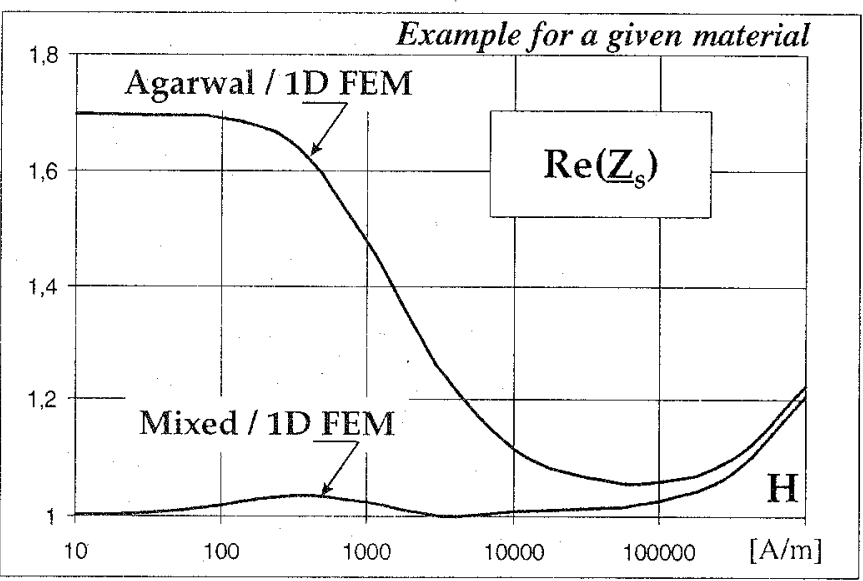

Fig. 7: comparison of Agarwal's theory, mixed model (Eq. 4) and ID-FEM.

\section{Comparison with Agarwal's theory.}

Figure 7 shows an example of results for the real part of the surface impedance, or for the active power density (both are equivalent). The comparison is done with the 1D-FEM, which is supposed to be exact. Agarwal's result is roughly correct for about $100,000 \mathrm{~A} / \mathrm{m}$ and is completely fanciful for lower or larger fields. It shows the positive contribution of the mixed impedance proposed by Guérin: the mixed value is nearly correct up to $100,000 \mathrm{~A} / \mathrm{m}$, however the balance factor $\alpha(12)$ has been optimized for this result and the reactive part does not present the same quality.

Considering its low cost, the method of numerical computation of the complex surface impedance is certainly the most relevant.

\section{Coupling with $3 D$ BEM and convergence.}

Then we will use these values of $\underline{Z}_{S}(10)$ for the $3 D$ $\mathrm{BEM} / \mathrm{FEM}$ magnetodynamic resolution. The non-linear convergence is obtained by an iterative process (each nodal value of the surface impedance depends on the field intensity, which depends on the 3D-BEM/Surface-FEM solution, and so on). Generally, 3 or 4 steps are sufficient (Fig. 8).

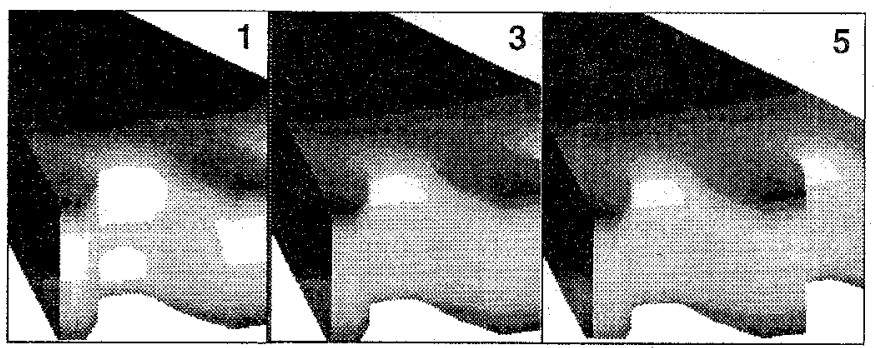

Fig. 8: Surface current density on a cogwheel (induction hardening) Example of non tinear convergence (steps 1,3 and 5)

\section{TEST PROBLEM AND VALIDATION}

As previously mentioned, this method is not exact, because the real variations are not exactly sinusoidal. How accurate will our results be, for global values (power) as for local values?

A further publication will present validations from the thermal behavior, in connection with measures. In this paper, we carry our attention on the comparison with other numerical methods. The difficulty is to find other methods allowing to solve the same type of problem with $3 \mathrm{D}$ structures. As compromise, we propose to use an axisymmetric structure and a 2D notorious software [9]. 


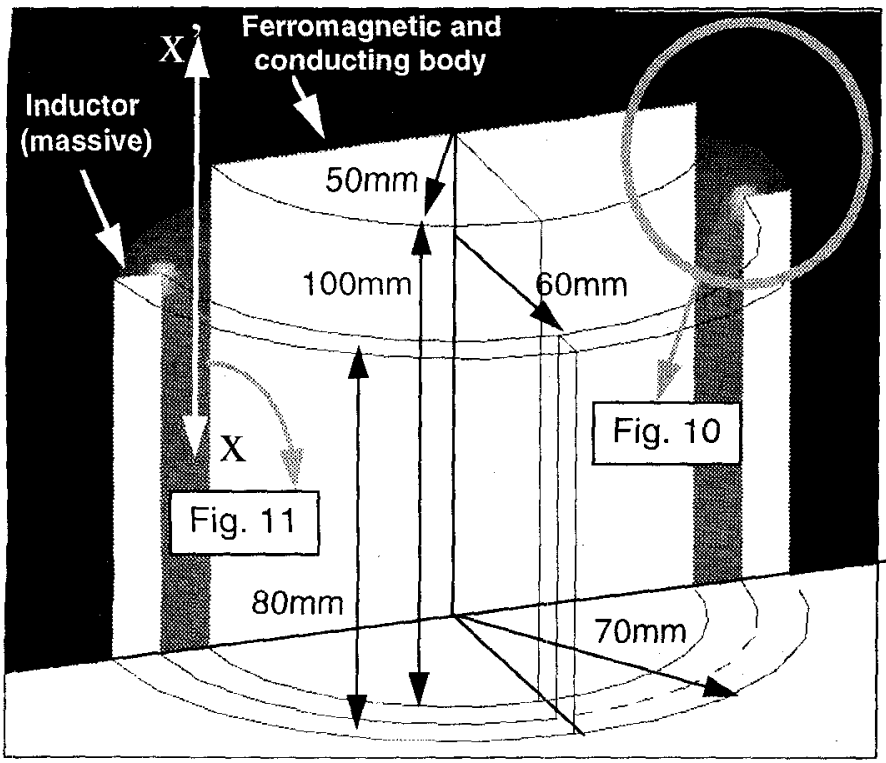

Fig. 9: Axisymmetric test problem

The test problem is very simple (Fig. 9). It is composed of a massive inductor $\left(\sigma=0.559 .10^{8}[\mathrm{~S} / \mathrm{m}], \mu_{,}=1 ., \mathrm{f}=10^{4}[\mathrm{~Hz}]\right)$ and of a ferromagnetic cylinder with following properties :

$$
\begin{aligned}
& \sigma=0.275 .10^{7} \quad[\mathrm{~S} / \mathrm{m}] \\
& \mathrm{B}(\mathrm{H})=\mu_{0} \mathrm{H}+\mathrm{C}_{1} \mathrm{a} \tan \left(\mu_{0} \mathrm{C}_{2} \mathrm{H}\right) \quad \text { with: } \\
& \mathrm{C}_{1}=\frac{2}{\pi} \mathrm{B}_{\mathrm{sal}} \quad \mathrm{C}_{2}=\left(\mu_{\mathrm{r} .0}-1\right) / \mathrm{C}_{1} \\
& \mathrm{~B}_{\mathrm{sat}}=2.2[\mathrm{~T}] \quad \mu_{\mathrm{r}, 0}=1000 .
\end{aligned}
$$

For the $2 D$ results, we have first used a step-by-step method («exact» method), then the complex approximation regularly used for non linear problems[9]. The electric source is the voltage.

For the 3D tests, the proposed formulation has been implemented in the software PHI3D [8]; linear and non-linear surface impedances are used respectively for the inductor and for the cylinder. The electric source is the total current in the

\begin{tabular}{|c|c|c|c|c|}
\hline a) Direct comp & utation of powe & (volume/surf? & ace integrall & \\
\hline & $20 \mathrm{~V}, 10 \mathrm{kHz}$ & & Cylinder & \\
\hline & RMS Current [A] & & $P[W]$ & Q [VAr] \\
\hline $2 \mathrm{D}$ - complex & 3355 & (1) & 29318 & 20168 \\
\hline 2D - step/step & 3175 & (2) & 29345 & \\
\hline 3D - BEM+Zs & 3175 & (3) & 32536 & 20564 \\
\hline b) Computatior & from electric s & & & \\
\hline & $20 \mathrm{~V}, 10 \mathrm{kHz}$ & & Inductor: & Cylinder: \\
\hline & RMS Current [A] & phase $\left[^{\circ}\right]$ & $P[W]$ & $P[W]$ \\
\hline $2 D-c$ & 3355 & 119,0 & 1397 & 31133 \\
\hline $2 D-s$ & 3175 & 122,2 & 1209 & 32628 \\
\hline ) $P+j Q=$ & $p+j q) \cdot d p$ & (2) $P=$ & $\int[$ & 7. $d t$ \\
\hline & & & $T$ colinder & \\
\hline (3) $P+j Q=$ & $\int H_{S}^{2} \underline{Z}_{S} \cdot d s$ & (4) $P+j C$ & $2=U \cdot I^{*}-$ & $(p+j q) \cdot d v$ \\
\hline & crlinder) & & & tuctor \\
\hline 5) $P=\frac{1}{2}$ & $i(t)-$ & $\mid v] . d t$ & & \\
\hline & Indintor & & & \\
\hline
\end{tabular}
inductor.

TABLE I

POWER FOR THE TEST-PROBLEM

\section{A. Global values:}

The FEM (complex or step by step) gives directly access to power by volume integrations; unfortunately, the numerical accuracy is poor in the cylinder because of the skin effect. Better results are obtained from electric power (true RMS value for the step by step method).

The FE/step-by-step and the proposed 3D methods give equivalent results. The complex $2 \mathrm{D}$ method over-estimates the current and minimizes the active power (see table I for $\mathrm{U}=20 \mathrm{~V}$ ). This result has been confirmed for other voltages.

\section{B. Local values}

It is difficult to carry out pertinent comparisons for local values. For example, figure 10 presents the modulus of the magnetic field at the instant when the current in the inductor is maximum. The values obtained with the step by step method are superimposed on those obtained with the method proposed. The correlation is good, but not excellent. This little shifting for a given instant has to exist, because we compute harmonic fields while the step by step solution is not sinusoidal.

This explanation is supported by the comparison of the true RMS values of $\mathrm{H}$ (Fig. 11): in this case, the difference vanishes. Only the 2D complex methods gives less perfect results, and this is coherent with its greater error on power.

From these two comparisons, it seems that the accuracy of the non linear surface impedance method is as good - or better - as the normal complex FEM, and it is much cheaper.

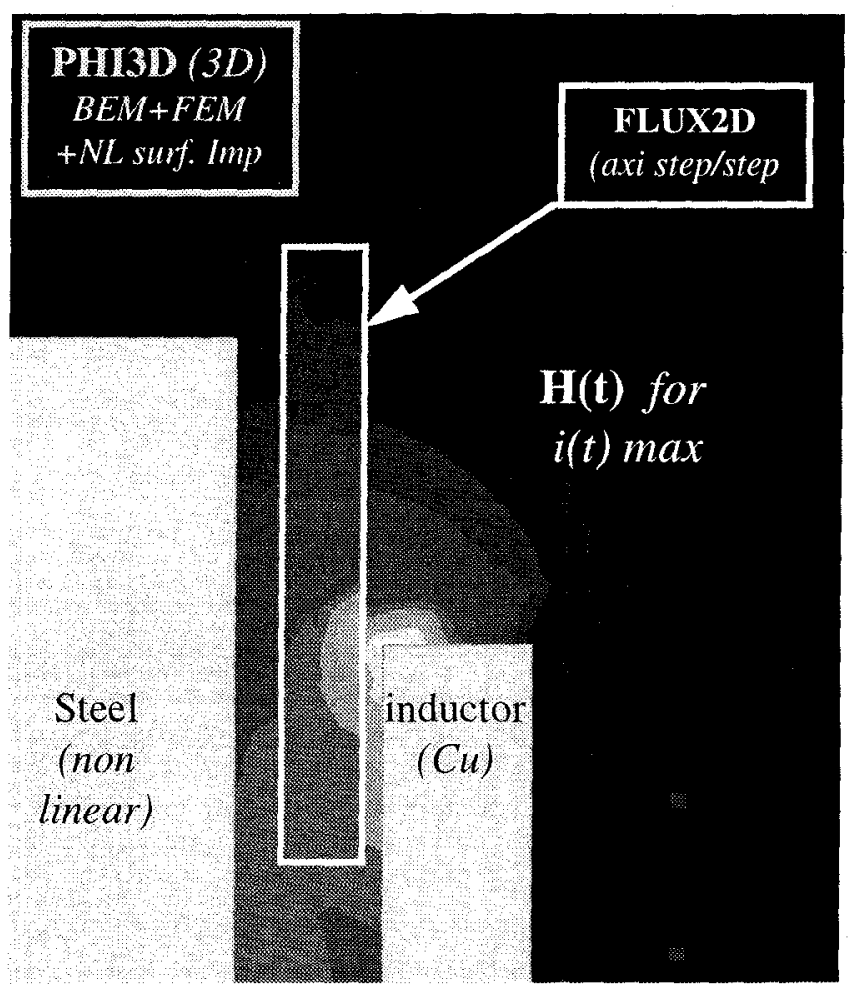

Fig. 10: Comparison with axi-FEM (step-by-step): magnetic field modulus $\mathrm{H}(\mathrm{t})$

(corresponding to the maximum value of source current) 


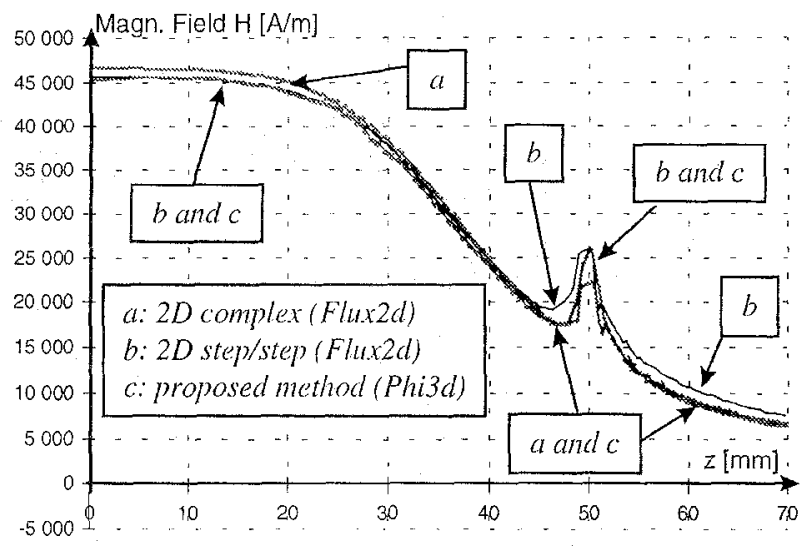

Fig. 11: Comparison with axi-FEM:

True RMS values of mushetic field (line XX'. Fig. 9)

Finally, we want to point out how fine the mesh of the skin depth has to be in order to get correct results, when using the Finite Element Method (complex or step by step formulation): we used 15 second order elements for the $2 \mathrm{D}$ resolutions, 50 first order elements in 10 . Traditionally, 2 second order elements are recommended, that seems to be really insufficient, particularly for non-linear materials!

\section{COUPLing With Thermal Computation}

This 3D BEM/FEM method is destined to be coupled with a FE thermal computation for induction hardening purpose [6]. This coupling is weak: two different packages are used: Phi3d [8] for electromagnetics and Flux-Expert [7] for thermics. For a given temperature, Phi3d computes the surface power density which is transferred to Flux-Expert. The evolution of temperature is then computed step by step until it varies sufficiently to change the electromagnetic characteristics of the material. The surface distribution of temperature is then re-transferred to phi3d for a new electromagnetic computation. This iterative process may continue until reaching a condition on the temperature or on the length of the process [1].

Figure 11 shows such a process applied for the steal hardening of a cogwheel.

\section{CONCLUSION}

For small skin depth, non-linearities are difficult to modelize even with a volume finite element method because of the number of elements required. The method proposed here is of course not exact but it leads to better results than any other one. Furthermore its computation cost remains acceptable. Validation of the thermal results is currently in progress. Next development will concern the computation of the surface impedance for rotating excitation fields, and the coupling with circuit equations for the electric input.

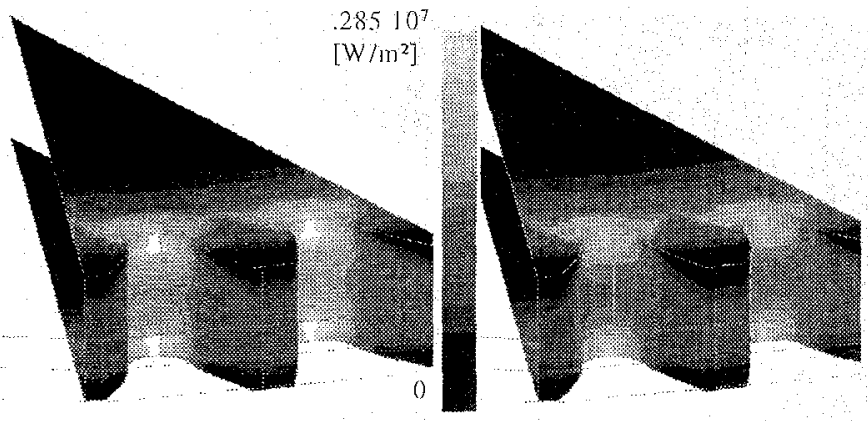

(a): surfuce power density at the beginning (left. $T=20^{\circ} \mathrm{C}$ ) and at the end (right. $20^{\circ} \mathrm{C}<T<605^{\circ} \mathrm{C}$ ) of the process.

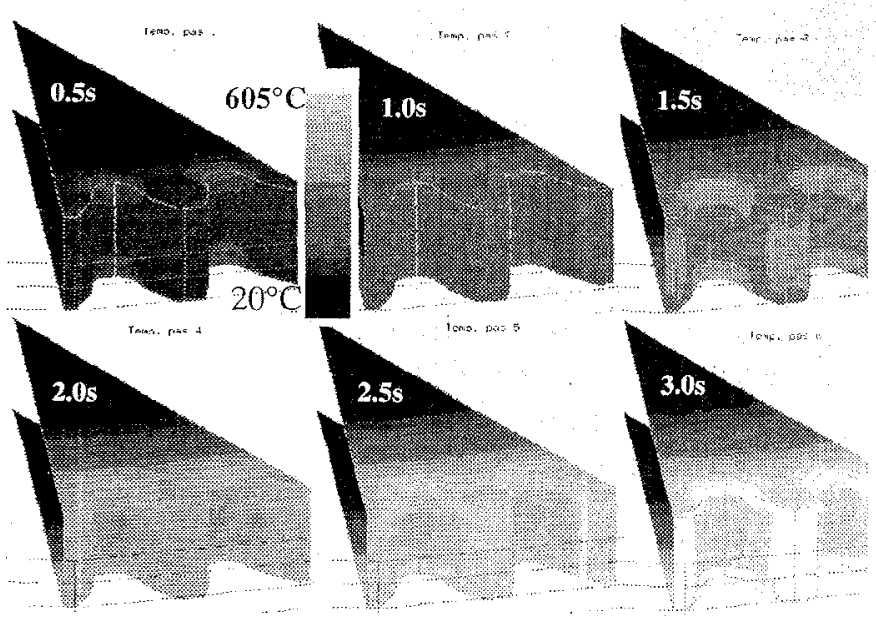

(b): distribution of sufface temperature at different instants (T-scale: 20 (e) $\left.605^{\prime \prime} \mathrm{C}\right)$.

Fig. 12: steel hardening of a cogwheel.

\section{REFERENCES}

[1] S. Wanser, "Simulation des phénomènes de chauffage par induction." Ph D Thesis ECL95-06 (France), 02/95. CEGEly, BP 163, 69131 Ecully Cedex (France).

[2] L. Krähenbühl, D. Muller, "Thin layers in electrical engineering. Example of shell models in analysing eddy currents by boundary and finite element methods," IEEE T-Mag, Vol. 29, n'2, pp. 1450-1455.

[3] P.D. Agarwal, "Eddy current losses in solid and laminated iron," Trans. A.I.E.E. 1959,42 , Pt 1, pp. 169-181

[4] Ch. Guérin, G. Meunier, "Surface impedance for 3D non-linear eddy. current problems; application to loss computation in transformers," Compumag Berlin, Germany, july 10-13 1905, conference record pp. 724-725.

[5] A. Bossavit, "Le chauffage par induction des pieces d'acier: aperçus théoriques," $R G E, 1 / 86, \mathrm{pp})$. (1)-32.

[6] S. Wanser, L. Krähenbuihl, A. Nicolas, "Computation of 3D induction hardening problems by combined finite and boundary element methods," IEEE T-Mag, Vol. 30, n\%5, pp.3320-3323.

[7] Flux-Expert user manual. DT2r Corp., 8 ch. des Prêles, ZIRST - 38240 Meylan (France).

[8] L. Krähenbühl, A. Nicolas and L. Nicolas, "The CAD package Phi3d for the computation of electric and magnetic fields in 3D devices," Compel, Vol. 9, suppl. A, pp. 185-189, 1990.

[9] Flux2d user manual. Magsoft Corp., Troy, New York (U.S.A.). 